\title{
Percutaneous Treatment Options for Recurrent Mitral Valve Disease after Failed Mitral Valve Surgery
}

\author{
Damiano Bianda ${ }^{1}$, Oliver Gaemperli², Roberto Corti ${ }^{3}$, Maurizio Taramasso ${ }^{4}$, Juerg Gruenenfelder ${ }^{3}$, \\ Francesco Maisano ${ }^{4}$ and Patric Biaggi ${ }^{3 *}$ \\ ${ }^{1}$ University of Zurich, Zurich, Switzerland \\ ${ }^{2}$ Department Cardiology, University Heart Center Zurich, Zurich, Switzerland \\ ${ }^{3}$ Heart Clinic Hirslanden, Zurich, Switzerland \\ ${ }^{4}$ Department Cardiovascular Surgery, University Heart Center Zurich, Zurich, Switzerland
}

Received: 18 January, 2017; Accepted: 10 March, 2017; Published: 20 March, 2017

*Corresponding author: Patric Biaggi, MD, Heart Clinic Hirslanden, HerzKlinik Hirslanden, Witellikerstrasse 40, 8032 Zurich, Switzerland, Tel: +41 4438797 00, Fax: +41 4438797 10; E-mail: patric.biaggi@hirslanden.ch

\begin{abstract}
Objectives: Percutaneous treatment options have been described as an alternative to redo-surgery in high-risk patients with recurrent Mitral Regurgitation (MR) after failed Mitral Valve (MV) surgery. We aim to analyze the outcome of percutaneous MV interventions in such patients.
\end{abstract}

Methods: Seventeen consecutive surgical intermediate to highrisk patients with recurrent MV disease not considered suitable for redo surgery were analyzed. Percutaneous MitraClip repair $(n=11)$, valve-in-ring $(n=3)$ or valve-in-valve $(n=3)$ replacement were performed.

Results: Median age was 76.0 years (53.6 to 89.4 years). Median EuroSCORE II and STS mortality score were $4.5 \%$ (0.5 to $14.4 \%$ ) and $4.9 \%$ (1.5 to $20.9 \%$ ), respectively. Pre-operative MR grade was moderate-severe $(n=4,24 \%)$ or severe $(n=13,76 \%)$. Interventional success was obtained in all but three cases (82\%). 30 day survival rate was $100 \%$. At last follow-up (mean 270 days, range 31 to 1559 days), the overall survival rate was $76 \%$. MR grade was none-mild in $76 \%$ and moderate in $24 \%$ of patients. Reduction of dyspnea was achieved in all but 2 patients $(88 \%)$

Conclusion: Percutaneous MV treatments after failed MV surgery are feasible and associated with a lower than expected periinterventional mortality in carefully selected patients not suitable for redo MV surgery. The interventions proved effective regarding reduction in MR and symptoms as well as lowering of pulmonary pressure.

Keywords: Percutaneous mitral valve interventions; Transcatheter mitral valve replacement; MitraClip; Valve-in-ring; Valve-in-valve; Redo mitral valve surgery

\section{Abbreviations}

3D: Three Dimensional; MC: MitraClip; MR: Mitral Regurgitation; MS: Mitral Stenosis; NYHA: New York Heart Association; TEE: Transesophageal Echocardiography; TR: Tricuspid Regurgitation; VIR: Valve-in-Ring; VIV: Valve-in-Valve

\section{Introduction}

Mitral valve regurgitation (MR) is one of the most common valvular diseases [1]. For severe symptomatic mitral valve disease, mitral valve repair or replacement is highly recommended [2]. In the last few years, a better long-term outcome in patients undergoing repair instead of replacement has been shown for patients with primary mitral regurgitation $[3,4]$. For patients with ischemic MR, there appears to be no benefit of repair over replacement [5]. In surgical high-risk patients, percutaneous mitral valve repair using the MitraClip (MC) has shown to be an important alternative [6,7]. However, surgical mitral valve replacement or repair is more effective in reducing MR than minimal-invasive procedures, so that surgical correction of MR is still regarded the gold standard in patients with a low-risk profile [8].

Nevertheless, the initial surgical treatment may fail over time, resulting in recurrent mitral valve disease. If the patient is old or otherwise at high-risk for redo-surgery, the management of recurrent mitral valve disease can be challenging. For such patients, percutaneous treatment approaches are commonly preferred and are associated with good peri-interventional success $[9,10]$. Percutaneous mitral valve repair with a MC has been described as a valid option to surgery [11]. However, MC insertion is not always technically feasible, so that other interventions like percutaneous valve-in-ring (VIR) and valve-invalve (VIV) replacement have been described [12].

The aim of this study was to analyze the outcome of the three percutaneous therapy options (MC in repaired mitral valve, VIR and VIV replacement) in a cohort of selected high-risk and symptomatic patients with a recurrent mitral valve disease not suitable for redo surgery.

\section{Methods}

\section{Population}

Our retrospective study included 17 symptomatic patients who presented with recurrent mitral valve pathology (MR or mitral stenosis (MS)) after initial mitral valve surgery between September 2011 and September 2015. All patients were reviewed by the local heart team (either at the University Hospital of Zurich or at the Heart Clinic Hirslanden Zürich). The heart teams were composed of cardiac surgeons, interventional 
cardiologists, cardiac imaging specialists, clinical cardiologists and cardiac anesthetists. The decision on how to proceed with a patient was taken considering all relevant clinical, anatomical and technical aspects. The clinical assessment included the two most commonly used surgical risk scores (EuroSCORE II and STS Risk of Mortality) [13,14]. Age itself is an important risk factor. While lower age was not automatically considered low surgical risk, all octogenarians were considered high risk for redo mitral valve replacement [15]. In additions, the heart teams also considered clinical risk factors missed by both scores, including frailty (clinically assessed, no formal score used), presence of osteoporosis, liver disease, previous complicated surgical course, status post chest radiation and simply the patients unwillingness to undergo redo cardiac surgery at a reduced clinical status. One patient refused redo-surgery despite low peri-operative risk and insisted on a catheter based intervention. Depending on the type of procedure, patients gave informed consent to the appropriate national registry (MitraSwiss registry for MC or the Swiss TAVI registry for VIR and VIV). The study protocol was approved by the ethical committee of Zurich, Switzerland.

\section{Clinical data}

Baseline and follow-up clinical data as well as echocardiographic and invasive data were gathered by reviewing the patient's chart. Follow-up data also consisted of data from the last available report by a cardiologist or family physician.

\section{Procedure}

All redo procedures of this study were elective. The type of percutaneous intervention was defined and performed by the local heart team: percutanous edge-to-edge repair by MC in formerly repaired mitral valves, percutaneous mitral VIR replacement or percutaneous mitral VIV replacement (Figure 1).

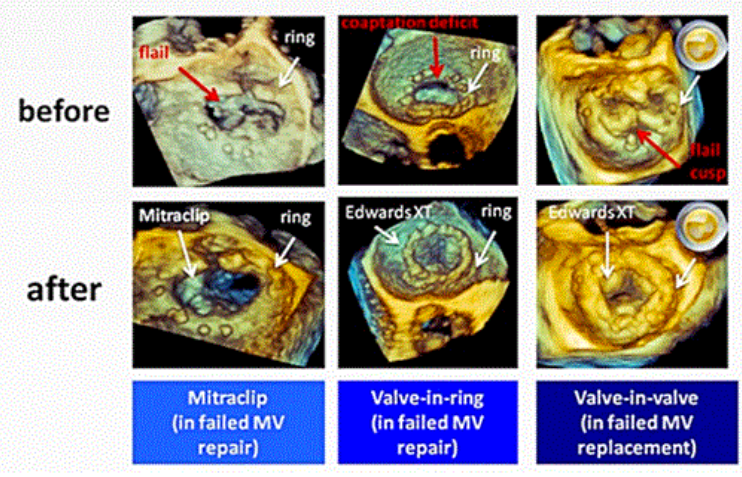

Figure 1: Types of percutaneous mitral valve interventions Legend: Examples of the three performed interventions are shown before $(A, C, E)$ and after $(B, D, F)$ the procedure. A) Patient with a recurrent flail of the P2 segment after mitral valve repair with ring annuloplasty ring and B) after MitraClip implantation. C) Patient with restrictive posterior mitral leaflet after ring annuloplasty, resulting in severe recurrent mitral regurgitation and D) after transapical valve-in-ring implantation of a $26 \mathrm{~mm}$ Sapien XT prosthesis. E) Patient with a degenerated mitral valve prosthesis with flail of the posterolateral cusp, and F) after transapical valve-in-valve implantation of a $26 \mathrm{~mm}$ Sapien XT prosthesis.

\section{MitraClip}

The MC intervention as performed at the two centers has been described else were [16]. If feasible, the MC procedure was the procedure of choice in all patients post MV repair and the only option in cases with anuloplasty rings too large for implantation of a Sapien prosthesis. Both pre- and peri-interventional threedimensional (3D) transesophageal echocardiography (TEE) was performed to ensure optimal imaging guidance and assessement of peri-interventional MR [17]. Meticulous care was taken to ensure visualisation and sufficient height of the posterior mitral valve leaflet and to guarantee minimal mitral valve opening before the procedure $(>3 \mathrm{~cm} 2)$. If the mitral valve orifice area after redo MC was expected to be lower than $2 \mathrm{~cm} 2$, we opted for a valve in ring procedure. Peri-interventional measurement of transvalvular gradients by continous wave Doppler was used to assess the peri-interventional change of mitral valve opening area [18].

\section{Valve-in-ring mitral valve replacement}

As with the MC procedure, pre-interventional 3D TEE and computed tomography was used to assess the exact size and height of the implanted annuloplasty ring as well as the length, calcification and mobility of the anterior mitral leaflet and the width of the left ventricular outflow tract (Figure 2).

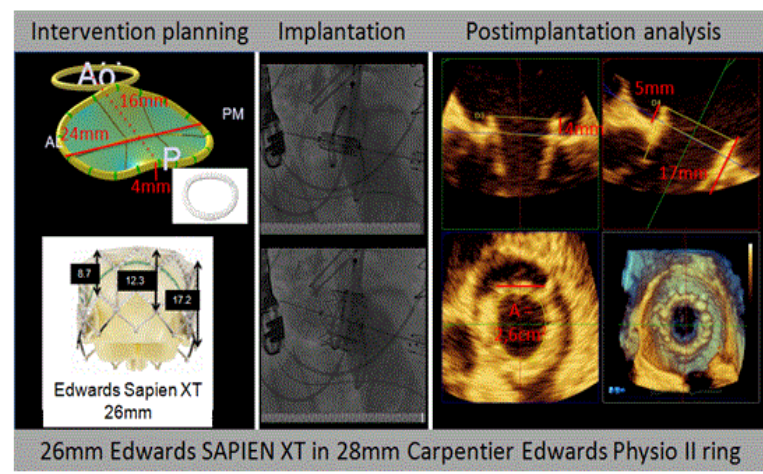

Figure 2: Transapical mitral valve-in-ring replacement

Legend: Image demonstrating important steps for valve-in-ring replacement. Before the intervention, details of the implanted annuloplasty system, in this case a $28 \mathrm{~mm}$ Edwards Physio II ring, are studied in vivo using 3D TEE and specialized software for post-processing. The height of the ring is estimated at $4 \mathrm{~mm}$, and the landing zone (skirt zone) of the chosen prosthesis (in this case a $26 \mathrm{~mm}$ Sapien XT prosthesis) measures $8.7 \mathrm{~mm}$. During the intervention, precise positioning is guaranteed using fluoroscopy. Post implantation, the position of the prosthesis within the ring is re-analysed. In this case, optimal position could be achieved, leaving no paravalvular regurgitation at all.

Based on these measurements, the size of the percutanous heart prosthesis (Edwards Sapien XT and Edwards Sapien 3) was defined. Prostheses were implanted using a transapical [9] or transseptal approach, depending on anatomy and concomitant pulmonary disease. The prosthesis was deployed under rapid pacing and simultaneous fluoroscopic and echocardiographic guidance. 


\section{Valve-in-valve mitral valve replacement}

VIV mitral procedures were performed using an apical or transseptal apporach as described above for VIR and as previously described by others [10]. The choice of valve prosthesis was based on pre-interventional 3D TEE imaging, computed tomography and in accordance with the mitral VIV app by Dr. Vinayak Bapat (http://www.ubqo.com/vivmitral) and the website www.valveguide.ch [19].

\section{Definitions of outcome}

MR, MS and tricuspid regurgitation (TR) were graded according to European Association of Cardiovascular Imaging's recommendations [20]. Procedural success was defined as modified device success and absence of adverse events at 30 day post-intervention according to the MVARC criteria [21].

\section{Statistics}

Continuous data are expressed as median and range (minimal-maximal value), and categorical data as number and percentage (\%). No p-values were calculated due to the small number of subjects. We used Excel version 2007 for statistical analysis.

\section{Results}

\section{Baseline characteristics}

Patients' baseline characteristics are summarized in Tables 1 and 2.

\begin{tabular}{|c|c|}
\hline & Population $(n=17)$ \\
\hline - male, n (\%) & $11(65 \%)$ \\
\hline $\begin{array}{l}\text { - age at redo intervention, years (range) } \\
\text { - duration of hospital stay, days (range) }\end{array}$ & $\begin{array}{c}76.0(53.6 / 89.4) \\
5(2 / 11)\end{array}$ \\
\hline 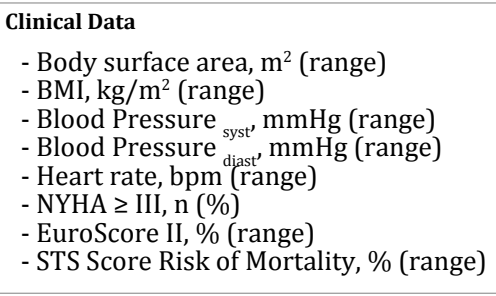 & $\begin{array}{c}1.9(1.2 / 2.5) \\
25.5(17.4 / 39.7) \\
118(93 / 162) \\
70(52 / 88) \\
69(49 / 91) \\
12(71 \%) \\
4.5(0.5 / 14.4) \\
4.9(1.5 / 20.9)\end{array}$ \\
\hline 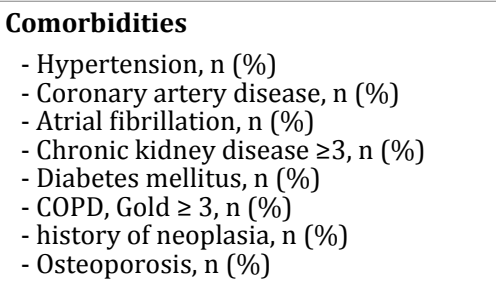 & $\begin{array}{l}8(47 \%) \\
3(18 \%) \\
4(22 \%) \\
8(47 \%) \\
0(0 \%) \\
0(0 \%) \\
5(29 \%) \\
2(12 \%)\end{array}$ \\
\hline $\begin{array}{l}\text { Drugs } \\
\text { - Diuretics, n (\%) } \\
\text { - ACE-inhibitors, n (\%) } \\
\text { - Beta blockers, n (\%) } \\
\text { - Angiotensin II receptor antagonist, n } \\
\text { (\%) } \\
\text { - Spironolactone, n (\%) } \\
\text { - Statins, n (\%) }\end{array}$ & $\begin{array}{c}14(82 \%) \\
7(41 \%) \\
11(65 \%) \\
7(41 \%) \\
5(29 \%) \\
9(53 \%)\end{array}$ \\
\hline $\begin{array}{l}\text { All data are given as median (range) or number } \\
\text { BMI: body mass index; NYHA: New York Heart } \\
\text { thoracic surgeons; COPD: chronic obstructive p }\end{array}$ & $\begin{array}{l}\text { rcentage). Abbreviations: } \\
\text { iation; STS: Society of } \\
\text { nary disease. }\end{array}$ \\
\hline
\end{tabular}

Table 2: Baseline echocardiographic, invasive and laboratory measurements

\begin{tabular}{|l|c|}
\hline Echocardiography & $\begin{array}{c}\text { Population } \\
\text { (n=17) }\end{array}$ \\
\hline - Ejection fraction, \% (range) & \\
- LVEDV $_{\mathrm{i}}, \mathrm{mL} / \mathrm{m}^{2}$ (range) & $63(40 / 72)$ \\
- LAV ${ }_{\mathrm{i}}$ mL/m ${ }^{2}$ (range) & $70(40 / 114)$ \\
- RV/RA, mmHg* (range) & $68(41 / 98)$ \\
- MR $\geq$ moderate, $\mathrm{n}(\%)$ & $49.2(20 / 70)$ \\
- diastolic transmitral gradient, & $17(100 \%)$ \\
mmHg (range) & $3.2(1 / 11)$ \\
- TR grade $\geq$ moderate**, $\mathrm{n}(\%)$ & $4(27 \%)$ \\
\hline Invasive hemodynamic (n $=8)$ & \\
- Systolic PAP, mmHg (range) & \\
- Pulm. VR, mmHg*min/mL & $58(48 / 75)$ \\
(range) & $373(240 / 807)$ \\
\hline Labor & \\
- Hemoglobin, g/L (range) & \\
- Glomerular filtration rate, ml/ & $130(95 / 157)$ \\
min (range) & $53(24 / 95)$ \\
\hline All data are given as median (range) & \\
\hline
\end{tabular}

All data are given as median (range) or numbers (percentage). Abbreviations: $\operatorname{LVEDV}_{\mathrm{i}}$ : left ventricular end diastolic volume, index; $\mathrm{LAV}_{\mathrm{i}}$ : left atrial volume, index; RV/RA: right ventricle/ right atrium ratio; MR: mitral regurgitation; TR: tricuspid regurgitation; PAP: pulmonary arterial pressure; VR: vascular resistence. ${ }^{*} \mathrm{n}=13,{ }^{* *} \mathrm{n}=15$

MR grade at baseline was moderate-severe $(n=4$, $24 \%)$ or severe $(n=13,76 \%)$. Two patients presented with a concomitant moderate $(n=1,6 \%)$ and severe $(n=1,6 \%)$ MS, respectively. 8 (47\%) patients had a EuroSCORE II $>5$ and/ or a STS risk mortality score $>8.8$ of the remaining 9 patients with lower risk scores had one or several clinical indicators for a complicated perioperative course and were therefore turned down for redo cardiac surgery. Patient \#9 insisted on a minimal invasive procedure despite a low-risk profile (EuroSCORE II $0.5 \%$ and STS Score Risk of Mortality 1.5\%). No patient with coronary artery disease had signs of ongoing ischemia or relevant stenosis in pre-intervention workup.

\section{Procedures}

The index open-heart operations on native mitral valves were mitral valve repair with $(n=8 ; 47 \%)$ or without $(n=6 ; 35 \%)$ ring-annuloplasty. A mitral valve replacement was performed in the remaining 3 patients (18\%, Table 3). Median time to repair failure was 7.9 years (range 1.0 to 18.6 years). The redointerventions were MC $(n=11,64 \%)$, VIR $(n=3,18 \%)$ and VIV 


\begin{tabular}{|c|c|c|c|c|c|c|c|c|}
\hline Patient & $\begin{array}{l}\text { Reason for } 1 . \\
\text { intervention }\end{array}$ & $\begin{array}{c}1 . \\
\text { intervention }\end{array}$ & $\begin{array}{c}\text { time to } \\
\text { failure }(y)\end{array}$ & Mode of failure & $\begin{array}{c}\text { Age at } 2 . \\
\text { Intervention } \\
\text { (y) }\end{array}$ & 2. Intervention & $\begin{array}{c}\text { MR Grade } \\
\text { at FU }\end{array}$ & Outcome \\
\hline 1 & $\begin{array}{l}\text { Mixed primary \& } \\
\text { secondary }\end{array}$ & $\begin{array}{c}\text { MV repair } \\
\text { without ring }\end{array}$ & 11.4 & $\begin{array}{l}\text { Recurrent } \\
\text { prolapse }\end{array}$ & 86 & MitraClip & Mild & $\begin{array}{c}\text { Death at } \\
31 \mathrm{~d}\end{array}$ \\
\hline 2 & Prolapse & $\begin{array}{l}\text { MV repair } \\
\text { without ring }\end{array}$ & 7.9 & $\begin{array}{c}\text { Recurrent } \\
\text { prolapse \& Flail } \\
\text { leaflet }\end{array}$ & 76 & MitraClip & Moderate & Alive \\
\hline 3 & Unknown & $\begin{array}{l}\text { MV repair } \\
\text { without ring }\end{array}$ & 7.7 & Degeneration & 84 & MitraClip & Mild & $\begin{array}{c}\text { Death at } \\
1093 d\end{array}$ \\
\hline 4 & Unknown & $\begin{array}{l}\text { MV repair } \\
\text { without ring }\end{array}$ & 11.1 & Flail leaflet & 76 & MitraClip (3x) & Moderate & Alive \\
\hline 5 & Prolapse & $\begin{array}{c}\text { MV repair } \\
\text { without ring }\end{array}$ & 7.0 & Flail leaflet & 69 & MitraClip & Mild & Alive \\
\hline 6 & Prolapse & $\begin{array}{c}\text { MV repair } \\
\text { without ring }\end{array}$ & 10.5 & $\begin{array}{l}\text { Recurrent } \\
\text { prolapse }\end{array}$ & 73 & MitraClip & Mild & Alive \\
\hline 7 & Prolapse & $\begin{array}{l}\text { MV repair with } \\
\text { ring }\end{array}$ & 18.6 & $\begin{array}{l}\text { Recurrent } \\
\text { prolapse }\end{array}$ & 69 & MitraClip in ring & Mild & Alive \\
\hline 8 & Unknown & $\begin{array}{l}\text { MV repair with } \\
\text { ring }\end{array}$ & 15.2 & Flail leaflet & 88 & MitraClip in ring & Mild & $\begin{array}{c}\text { Death at } \\
427 d\end{array}$ \\
\hline 9 & Flail leaflet & $\begin{array}{l}\text { MV repair with } \\
\text { ring }\end{array}$ & 1.4 & Flail leaflet & 62 & $\begin{array}{l}\text { MitraClip in ring } \\
\qquad(2 \mathrm{x})\end{array}$ & Moderate & Alive \\
\hline 10 & Functional MR & $\begin{array}{l}\text { MV repair with } \\
\text { ring }\end{array}$ & 3.2 & Dehiscence & 54 & $\begin{array}{l}\text { MitraClip in ring } \\
\qquad(3 \mathrm{x})\end{array}$ & None & Alive \\
\hline 11 & Prolapse & $\begin{array}{l}\text { MV repair with } \\
\text { ring }\end{array}$ & 1.2 & $\begin{array}{l}\text { Recurrent } \\
\text { prolapse }\end{array}$ & 58 & $\begin{array}{l}\text { MitraClip in ring } \\
\qquad(2 \mathrm{x})\end{array}$ & Moderate & Alive \\
\hline 12 & $\begin{array}{c}\text { Anulusdilatation \& } \\
\text { Tethering }\end{array}$ & $\begin{array}{l}\text { MV repair with } \\
\text { ring }\end{array}$ & 2.3 & $\begin{array}{c}\text { Restrictive } \\
\text { posterior leaflet }\end{array}$ & 79 & $\begin{array}{l}\text { Valve-in-ring, } \\
\text { Sapien XT 26mm } \\
\text { (transapical) }\end{array}$ & Mild & Alive \\
\hline 13 & $\begin{array}{c}\text { Infectious } \\
\text { endocarditis }\end{array}$ & $\begin{array}{l}\text { MV repair with } \\
\text { ring }\end{array}$ & 1.0 & $\begin{array}{l}\text { Degenerative/ } \\
\text { Stenotic }\end{array}$ & 73 & $\begin{array}{l}\text { Valve-in-ring, } \\
\text { Sapien } 326 \mathrm{~mm} \\
\text { (transapical) }\end{array}$ & None* & Alive \\
\hline 14 & Unknown & $\begin{array}{l}\text { MV repair with } \\
\text { ring }\end{array}$ & 7.0 & Flail leaflet & 77 & $\begin{array}{l}\text { Valve-in-ring, } \\
\text { Sapien } 329 \mathrm{~mm} \\
\text { (transseptal) }\end{array}$ & Mild & Alive \\
\hline 15 & $\begin{array}{c}\text { Infectious } \\
\text { endocarditis }\end{array}$ & $\begin{array}{l}\text { MV } \\
\text { replacement }\end{array}$ & 13.3 & Flail leaflet & 89 & $\begin{array}{l}\text { Valve-in-valve, } \\
\text { Sapien XT 26mm } \\
\text { (transapical) }\end{array}$ & None & $\begin{array}{c}\text { Death at } \\
394 d\end{array}$ \\
\hline 16 & Unknown & $\begin{array}{c}\text { MV } \\
\text { replacement }\end{array}$ & 9.8 & Flail leaflet & 80 & $\begin{array}{c}\text { Valve-in-valve, } \\
\text { Sapien } 329 \mathrm{~mm} \\
\text { (transapical) }\end{array}$ & None & Alive \\
\hline 17 & Post-rheumatic & $\begin{array}{l}\text { MV } \\
\text { replacement }\end{array}$ & 8.2 & Degeneration & 85 & $\begin{array}{l}\text { Valve-in-valve, } \\
\text { Sapien } 326 \mathrm{~mm} \\
\text { (transseptal) }\end{array}$ & None* & Alive \\
\hline
\end{tabular}

Abbreviations: MV: mitral valve; MR: mitral regurgitation; FU: Follow-up. *minimal trace of paravalvular regurgitation 
$(n=3,18 \%)$. The median duration of hospitalization was 5 days (range 2 to 11 days).

Technical success was obtained in 15 cases $(88 \%)$. The intra-procedural TEE in patient \#13 showed a left ventricular outflow tract obstruction after VIR procedure. A CoreValve Evolut R $29 \mathrm{~mm}$ prosthesis (Medtronic, Minneapolis, Minnesota) was successfully implanted in aortic position and effectively reduced outflow tract obstruction. Furthermore, trace of a paravalvular leak in mitral position was detected after the procedure but did not required treatment. At last examination (3 months), good clinical condition (NYHA I) and no signs of LVOT obstruction or worsening of paravalvular leak were observed [22]. For patient \#14 the first intended procedure was a MC repair. However, after initial MC placement, significant MR remained, and the insertion of a second MC would not have been possible due to a too small MV area. The MC intervention was thus aborted and successfully converted to a VIR (Sapien 3, 29mm) after removal of the clip. Patient \#17 developed a minimal paravalvular leak, which did not needed treatment. Patient \#15 required a pacemaker implantation for symptomatic sick sinus syndrome on the first post-operative day.

\section{0 day outcome}

30 day survival rate was $100 \%$ in the whole population. Procedural success according to the modified MVARC definitions was obtained in $82 \%$ of all interventions (14/17 cases). Apart from the patient requiring pacemaker implantation there were no cardiovascular events within the first 30 days.

\section{Follow-up}

\section{Survival}

Mean time to last follow-up was 270 days (range 31 to 1559 days) with an overall survival rate of $76 \%$. Four patients died in the follow-up time. Patient \#1 died 31 days after the intervention due to sepsis caused by a non-operable ileus. Patient \#3 died 1093 days after the intervention due to an acute pyelonephritis. Patient \#8 died at day 427 as a consequence of progressive kidney failure. Patient \#15 died 394 days after the procedure from unknown reason. The median age at death was 88.1 years (range 86.5 to 90.5 years).

\section{Further cardiac interventions}

Patient \#11 needed redo MC implantation on day 33 after the intervention due to insufficient symptom reduction, and remained asymptomatic thereafter. Patient \#16 (VIR and simultaneous percutaneous occlusion of the left atrial appendage) required the implantation of a cardiac resynchronization therapy device 116 days after the MC repair and a percutaneous valvein-homograft implantation of a Symetis Accurate transfemoral L prosthesis in this failing aortic homograft due to moderate-severe aortic regurgitation on day 538 after VIR, again reducing dyspnea to New York Heart Association (NYHA) class II. There were no other major adverse events registered in the whole population.

\section{Clinical findings}

NYHA class was available from 16 patients (94\%). Of those, a reduction in NYHA class was achieved in 14 cases $(88 \%$, Figure 3).

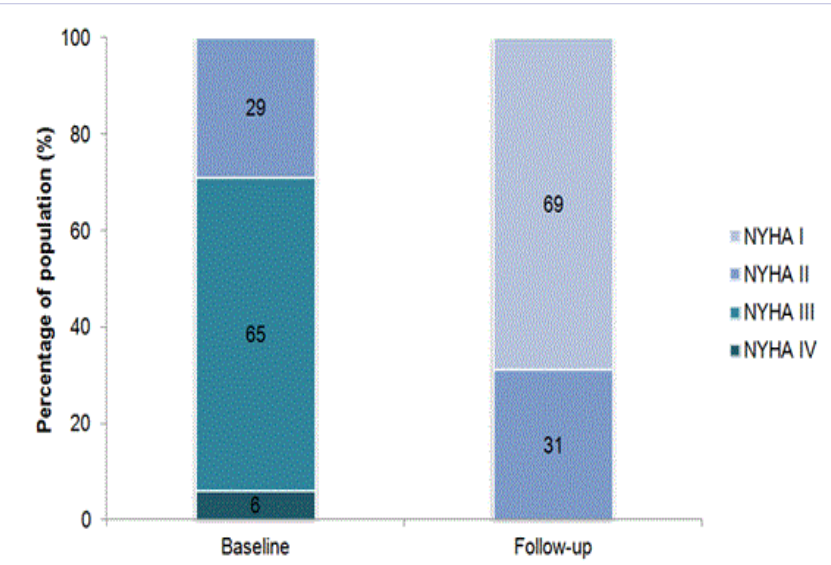

Figure 3: New York Heart Association (NYHA) classes at baseline and at follow-up.

Dyspnea reduction by 1, 2 or 3 classes was described in 6 (43\%), $7(50 \%)$ and $1(7 \%)$ patients, respectively. The two patients (12\%) who did not show improvements concerning dyspnea both underwent MitraClip repair.

\section{Echocardiographic findings}

MR grade was reduced in all patients after the second intervention (Figure 4).

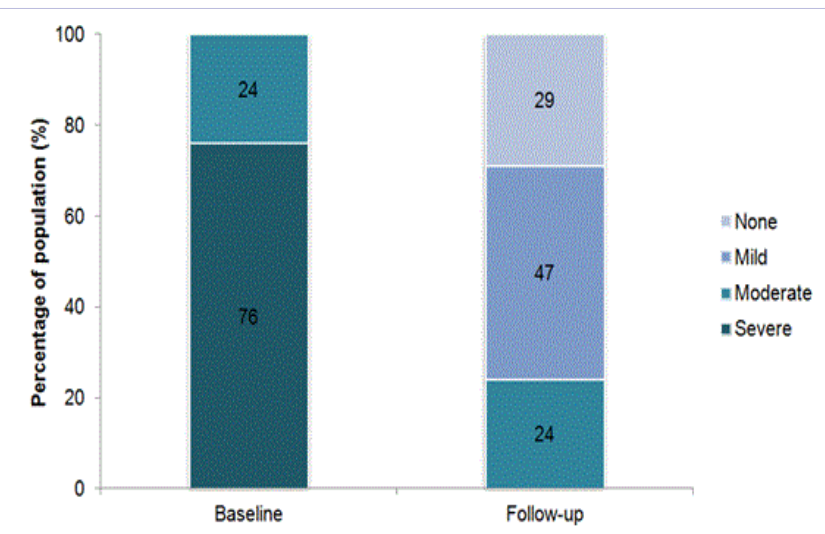

Figure 4: Degree of mitral regurgitation at baseline and at follow-up.

A moderate MR was observed in 4 patients (24\%), all of whom had undergone MC repair. All 4 patients were alive at last follow up. The two patients with intra-procedural complications showed both optimal echocardiographic findings. The paravalvular leaks in the patient \#13 and \#17 did not worsen until last follow-up. The median transmitral diastolic gradient increased from 3.2 $\mathrm{mmHg}$ at baseline to $5.2 \mathrm{mmHg}$ (range 3.0 to $9.0 \mathrm{mmHg}$ ). In 6 $(40 \%)$ of 15 available cases a reduction in TR was observed, 
while there was progression from a mild to a moderate TR after the intervention in $2 \mathrm{MC}$ patients $(13 \%)$. The percutaneous redointervention reduced the RV/RA pressure gradient by a median of $15.4 \mathrm{mmHg}$ (Figure 5).

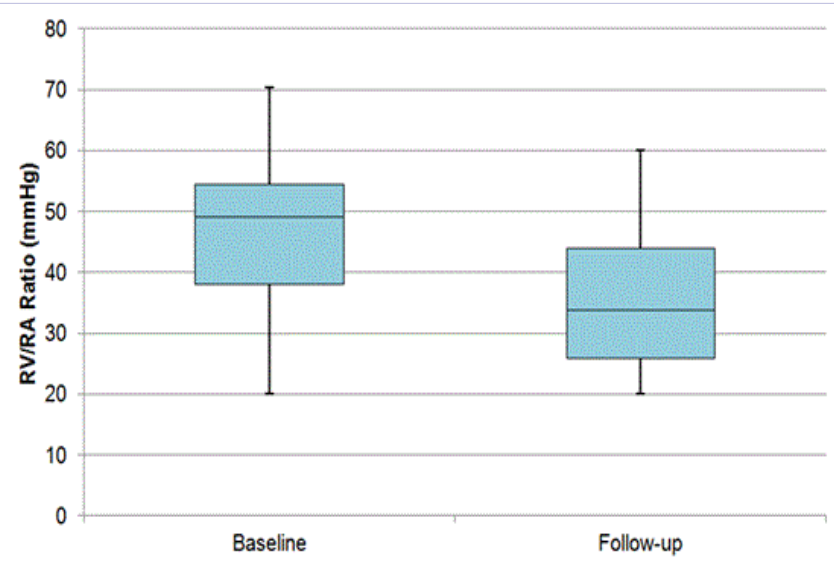

Figure 5: Right ventricular/right atrium pressure gradient $(\mathrm{mmHg}) \mathrm{ra}-$ tio at baseline and at follow-up.

Abbreviations: RV: Right ventricle; RA: Right atrium.

\section{Discussion}

Our retrospective analysis of 17 patients with failed surgical treatment of mitral valve disease suggests that a percutaneous redo strategy by either MC repair, VIR and VIV replacement is feasible and safe in carefully selected patients in whom redo surgery is no treatment option. The procedural success rate of $88 \%$ indicates that such procedures are technically challenging and should only be performed by a versatile heart team. The peri-interventional mortality rate of the percutaneous strategy was lower than calculated for redo-surgery, and at last follow-up there was no cardiac death.

\section{Outcome after Percutaneous Treatments}

Our results regarding procedural success, symptom reduction and survival are in line with the current literature $(9,10,23-27)$. Our mean follow-up survival was $76 \%$ and comparable to the published larger series, reporting survival rates of $71-90 \%[9,24,25]$. The largest series most recently documented survival rates of even $93 \%$, but the reported median follow-up in this series was only 40 days [23]. The 30 day mortality of $0 \%$ in our series was lower than the predicted survival by currents surgical scores. However, compared to other studies the patients in our study had relatively low predicted mortality scores $[10,25,26]$. The widely used risk scores (EuroSCORE II and STS mortality score) cover many, but not all relevant clinical risk factors. Frailty, liver disease, osteoporosis, status post chest radiation or a previously complicated surgical course or not included in the two mentioned scores. Age is part of the two scores, but merits special attention. While lower age does not automatically lead to lower surgical risk, higher age represents higher risk: Even at a very experienced center, primary mitral valve replacement in octogenarians showed a 90 day mortality rate of $31.6 \%$ [15]. 6 $(35 \%)$ of the 17 patients were octogenarians and thus per se at very high risk for redo surgery. These considerations highlight the importance of a sound clinical evaluation and discussion of all relevant clinical, anatomical and technical factors in the heart team. With the exception of one patient who refused redosurgery despite surgical low-risk scores, all patients were denied for redo-surgery by the heart team based on clinical judgment despite relative low mean risk scores. It is important to notice that the primary interventional goal in these highly comorbid and/or frail subjects, was the reduction of symptoms, and that goal was achieved in $88 \%$ of our patients.

\section{Impact of Treatment Strategy on Technical Result}

In addition to the data published on MC interventions in patients who had undergone mitral valve repair, our study demonstrates that MC treatment can also be safely and effectively offered to patients who had undergone repair without ring. In experienced hands, the MC intervention can be performed with a procedural time of around 30 minutes, thus offering the advantage of very short general anesthesia with minimal installations. On the downside, mitral valve repair by MC shows generally lower reduction of MR compared to mitral valve replacement [28]. In patients undergoing MC procedures in native valves, moderate or more residual MR was associated with worse outcome compared to mild or trace MR [29]. Based on the scarce literature it is not known whether the same holds true for patients with moderate residual MR following redo interventions using MC.

The valve prosthesis and access route of choice for redo transcatheter mitral valve replacement is a matter of debate. At this time, balloon-expandable aortic Sapien XT or Sapien 3 valves (Edwards Life sciences, Irvine, California) are predominantly reported in series describing percutaneous mitral VIR or VIV replacement $[9,12,23,25]$. Other types of valves are either under investigation, anatomically not suitable or described only in few number of studies. Based on the experiences of transcatheter aortic valve implantations, the initial access route for percutaneous mitral valve replacement was transapical, enabling good alignment with the ring/prosthesis in mitral position [10]. The development of third and fourth generation percutaneous valves with advanced steering capabilities of the catheter has promoted the transseptal approach in recent publications $[23,25,27]$. The use of the recently developed real time fusion imaging techniques like EchoNavigator (Phillips Healthcare, Amsterdam, Netherlands) further facilitates such interventions $[30,31]$. The rate of mild paravalvular MR of $33 \%$ in our cohort reflects the results of others [26]. Considering an occurrence rate of paravalvular MR after surgical MV replacement in native valves between $5-17 \%$ [32], these initial studies may suggest that paravalvular MR are more likely to occur during VIR and VIV. Access route might play a role in this regard as optimal axonal orientation of the prosthetic valve within the annuloplasty ring is more easily reached using an apical compared to a transseptal approach.

\section{Heart Team Approach}

To be able to offer therapy across such a large field of interventional cardiology and cardiac surgery asks for a true 
heart team approach. As is demonstrated by our data, it is not sufficient to be able to perform the one or other strategy. It is the ability to cope with unexpected events or complications that make such demanding interventions successful. In order to prevent emergency treatments, pre-interventional imaging plays a crucial role, in particular in patients with a repaired mitral valve. The decision whether a MC procedure or a percutaneous implantation of a mitral prosthesis is feasible and will result in durable benefit largely depends on morphological criteria, including definition of MR etiology, visibility of mitral valve leaflets, assessment of the mitral valve area and anterior mitral leaflet length, mobility and calcification as well as left ventricular outflow tract anatomy and annuloplasty ring characteristics $[18,33]$. The decision on the procedure of choice was taken based on a patient by patient analysis, taking into account all available clinical and imaging data as described above. Even then, prediction of procedural success was not perfect, as demonstrated by the two patients where the interventions were complicated and additional 'adhoc' strategies had to be developed during the procedure.

\section{Study limitations}

The main limitation of the present study is the small number of study subjects and the retrospective non-randomized study design. Moreover, follow-up time differed quite a bit between patients, so that statistically significant comparisons are difficult. As described above, mainly patients not suitable for redo-surgery due to elevated surgical risk were recruited, so that the interventions under investigation may not show similar results in patients with lower risk profile. It's important to point out that the supporting medical therapy was different from patient to patient. This may have additionally influenced outcome differences between the three procedures.

\section{Conclusion}

Percutaneous mitral valve treatments (MitraClip repair, valve-in-ring or valve-in-valve replacement) are feasible and safe treatment options for carefully selected patients with failing previous mitral valve operation not suitable for redo MV surgery. The interventions are associated with a lower than expected 30 day mortality. Overall survival during a mean follow-up time of 270 days was $76 \%$. The interventions proved effective regarding reduction in mitral regurgitation, lowering of pulmonary pressure as well as symptoms.

\section{Declarations}

This study was approved by the Zurich Cantonal Ethical Commission (KEK-ZH Nr. 2016-00044). Written informed consent based on the Human Research Ordinance of the Swiss Federal Law was obtained by every participant of the study.

\section{References}

1. Nkomo VT, Gardin JM, Skelton TN, Gottdiener JS, Scott CG, EnriquezSarano M. Burden of valvular heart diseases: a population-based study. Lancet. 2006;368(9540):1005-11. doi:10.1016/S01406736(06)69208-8

2. Nishimura RA, Otto CM, Bonow RO, Carabello BA, Erwin JP 3rd, Guyton RA, et al. 2014 AHA/ACC guideline for the management of patients with valvular heart disease: a report of the American College of Cardiology/American Heart Association Task Force on Practice Guidelines. J Thorac Cardiovasc Surg. 2014;148(1):e1-e132. doi:10.1016/j.jtcvs.2014.05.014

3. Thourani VH, Weintraub WS, Guyton RA, Jones EL, Williams WH, Elkabbani S, et al. Outcomes and long-term survival for patients undergoing mitral valve repair versus replacement: effect of age and concomitant coronary artery bypass grafting. Circulation. 2003;108(3):298-304. doi:10.1161/01.CIR.0000079169.15862.13

4. Enriquez-Sarano M, Schaff HV, Orszulak TA, Tajik AJ, Bailey KR, Frye RL. Valve repair improves the outcome of surgery for mitral regurgitation. A multivariate analysis. Circulation. 1995;91(4):1022-8

5. Goldstein D, Gelijns AC, Moskowitz AJ. Surgery for Severe Ischemic Mitral Regurgitation. N Engl J Med. 2016;374(20):1992-3. doi:10.1056/NEJMc1602607

6. Feldman T, Young A. Percutaneous approaches to valve repair for mitral regurgitation. J Am Coll Cardiol. 2014;63(20):2057-68 doi:10.1016/j. jacc.2014.01.039

7. Surder D, Pedrazzini G, Gaemperli O, Biaggi P, Felix C, Rufibach K, et al. Predictors for efficacy of percutaneous mitral valve repair using the MitraClip system: the results of the MitraSwiss registry. Heart. 2013;99(14):1034-40. doi:10.1136/heartjnl-2012-303105

8. Nishimura RA, Vahanian A, Eleid MF, Mack MJ. Mitral valve disease--current management and future challenges. Lancet. 2016;387(10025):1324-34. doi:10.1016/S0140-6736(16)00558-4

9. Descoutures F, Himbert D, Maisano F, Casselman F, de Weger A, Bodea 0 , et al. Transcatheter valve-in-ring implantation after failure of surgical mitral repair. Eur J Cardiothorac Surg. 2013;44(1):e8-15. doi:10.1093/ejcts/ezt155

10. Webb JG, Wood DA, Ye J, Gurvitch R, Masson JB, Rodés-Cabau J, et al. Transcatheter valve-in-valve implantation for failed bioprosthetic heart valves. Circulation. 2010;121(16):1848-57. doi:10.1161/ CIRCULATIONAHA.109.924613

11. Lim DS, Kunjummen BJ, Smalling R. Mitral valve repair with the MitraClip device after prior surgical mitral annuloplasty. Catheter Cardiovasc Interv. 2010;76(3):455-9. doi:10.1002/ccd.22547

12.Wilbring M, Alexiou K, Tugtekin SM, Arzt S, Ibrahim K, Matschke $\mathrm{K}$, et al. Pushing the limits-further evolutions of transcatheter valve procedures in the mitral position, including valve-in-valve, valve-in-ring, and valve-in-native-ring. J Thorac Cardiovasc Surg. 2014;147(1):210-9. doi:10.1016/j.jtcvs.2013.09.021

13. Nashef SA, Roques F, Sharples LD, Nilsson J, Smith C, Goldstone AR, et al. EuroSCORE II. Eur J Cardiothorac Surg. 2012;41(4):734-44. doi:10.1093/ejcts/ezs043

14. Puskas JD, Kilgo PD, Thourani VH, Lattouf OM, Chen EJD, et al. The society of thoracic surgeons 30-day predicted risk of mortality score also predicts long-term survival. Ann Thorac Surg. 2012;93(1):26-33; discussion -5. doi:10.1016/j.athoracsur.2011.07.086

15. Chikwe J, Goldstone AB, Passage J, Anyanwu AC, Seeburger J, Castillo JG et al. A propensity score-adjusted retrospective comparison of early and mid-term results of mitral valve repair versus replacement in octogenarians. Eur Heart J. 2011;32(5):618-26. doi:10.1093/ eurheartj/ehq331

16. Gaemperli O, Moccetti M, Surder D, Biaggi P, Hurlimann D, Kretschmar 0 , et al. Acute haemodynamic changes after percutaneous mitral valve repair: relation to mid-term outcomes. Heart. 2012;98(2):126-32. doi:10.1136/heartjnl-2011-300705

17. Gruner C, Herzog B, Bettex D, Felix C, Datta S, Greutmann M, et al. 
Quantification of mitral regurgitation by real time three-dimensional color Doppler flow echocardiography pre- and post-percutaneous mitral valve repair. Echocardiography. 2015;32(7):1140-6. doi:10.1111/echo.12809

18. Biaggi P, Felix C, Gruner C, Herzog BA, Hohlfeld S, Gaemperli O, et al. Assessment of mitral valve area during percutaneous mitral valve repair using the MitraClip system: comparison of different echocardiographic methods. Circ Cardiovasc Imaging. 2013;6(6):1032-40. doi:10.1161/ CIRCIMAGING.113.000620

19. Frank M, Ganzoni G, Starck C, Grünenfelder J, Corti R, Gruner C, et al. Lack of Accessible Data on Prosthetic Heart Valves. Int J Cardiovasc Imaging. 2016;32(3):439-47. doi:10.1007/s10554-015-0805-9

20. Frank M, Ganzoni G, Starck C, Grünenfelder J, Corti R, Gruner C, et al. Lack of Accessible Data on Prosthetic Heart Valves. Int J Cardiovasc Imaging. 2016;32(3):439-47. doi:10.1007/s10554-015-0805-9

21. Stone GW, Adams DH, Abraham WT, Kappetein AP, Généreux P, Vranckx P, et al. Clinical Trial Design Principles and Endpoint Definitions for Transcatheter Mitral Valve Repair and Replacement: Part 2: Endpoint Definitions: A Consensus Document From the Mitral Valve Academic Research Consortium. J Am Coll Cardiol. 2015;66(3):308-21. doi:10.1016/j.jacc.2015.05.049

22. Taramasso M, Nietlispach F, Schmid M, Maisano F. Corevalve Evolut R implantation to treat severe left ventricle outflow tract obstruction following mitral valve-in-ring: first-in-man report. Eur Heart J. 2016;37(3):317. doi:10.1093/eurheartj/ehv617

23. Taramasso M, Nietlispach F, Schmid M, Maisano F. Corevalve Evolut R implantation to treat severe left ventricle outflow tract obstruction following mitral valve-in-ring: first-in-man report. Eur Heart J. 2016;37(3):317. doi:10.1093/eurheartj/ehv617

24. Cheung A, Webb JG, Barbanti M, Freeman M, Binder RK, Thompson C et al. 5-year experience with transcatheter transapical mitral valvein-valve implantation for bioprosthetic valve dysfunction. J Am Coll Cardiol. 2013;61(17):1759-66. doi:10.1016/j.jacc.2013.01.058

25. Bouleti C, Fassa AA, Himbert D, Brochet E, Ducrocq G, Nejjari M, et al. Transfemoral implantation of transcatheter heart valves after deterioration of mitral bioprosthesis or previous ring annuloplasty. JACC Cardiovasc Interv. 2015;8(1 Pt A):83-91. doi:10.1016/j. jcin.2014.07.026
26. Seiffert M, Conradi L, Baldus S, Schirmer J, Knap M, Blankenberg S, et al. Transcatheter mitral valve-in-valve implantation in patients with degenerated bioprostheses. JACC Cardiovasc Interv. 2012;5(3):341-9. doi:10.1016/j.jcin.2011.12.008

27. Coylewright M, Cabalka AK, Malouf JA, Geske JB, Pollak PM, Suri RM, et al. Percutaneous mitral valve replacement using a transvenous, transseptal approach: transvenous mitral valve replacement. JACC Cardiovasc Interv. 2015;8(6):850-7. doi:10.1016/j.jcin.2015.01.028

28. Grasso C, Ohno Y, Attizzani GF, Cannata S, Immè S, Barbanti M, et al. Percutaneous mitral valve repair with the MitraClip system for severe mitral regurgitation in patients with surgical mitral valve repair failure. J Am Coll Cardiol. 2014;63(8):836-8. doi:10.1016/j.jacc.2013.09.045

29. Toggweiler S, Zuber M, Surder D, Biaggi P, Gstrein C, Moccetti T, et al. Two-year outcomes after percutaneous mitral valve repair with the MitraClip system: durability of the procedure and predictors of outcome. Open Heart. 2014;1(1):e000056. doi:10.1136/ openhrt-2014-000056

30. Sundermann SH, Biaggi P, Grunenfelder J, Gessat M, Felix C, Bettex D, et al. Safety and feasibility of novel technology fusing echocardiography and fluoroscopy images during MitraClip interventions. EuroIntervention. 2014;9(10):1210-6. doi:10.4244/EIJV9I10A203

31. Biaggi P, Fernandez-Golfin C, Hahn R, Corti R. Hybrid Imaging During Transcatheter Structural Heart Interventions. Curr Cardiovasc Imaging Rep. 2015;8(9):33. doi:10.1007/s12410-015-9349-6

32. Rihal CS, Sorajja P, Booker JD, Hagler DJ, Cabalka AK. Principles of percutaneous paravalvular leak closure. JACC Cardiovasc Interv. 2012;5(2):121-30. doi:10.1016/j.jcin.2011.11.007

33. Bail DH, Doebler K. The MitraClip System: a systematic review of indications, procedural requirements, and guidelines. Thorac Cardiovasc Surg. 2014;62(1):18-25. doi:10.1055/s-0033-1360509 